\title{
Midwives' experiences of witnessing traumatic hospital birth events: A qualitative study
}

\author{
Seyhan Çankaya ${ }^{1}$, Yasemin Erkal Aksoy ${ }^{1}$, and Sema Dereli Yllmaz ${ }^{1}$ \\ ${ }^{1}$ Selçuk University
}

May 3, 2021

\begin{abstract}
Aims: The aim of this study was to investigate in detail the traumatic birth experiences of midwives in the delivery rooms, and their attitudes, reactions, and coping strategies. Methods: The design of the study is descriptive and the purposive sampling method was used. This approach is ideal for a preliminary exploration of the nature of a phenomenon. Between October 2018 and January 2019, semi-structured interviews were conducted with a purposeful sample of midwives. The research was carried out with the participation of 29 midwives, who work in labour and birth room. They were asked to describe a particular stressful situation they had experienced during the birth process, their emotions about the event, and their coping strategies and support systems. All interviews were digitally recorded, stored in a database, and transferred to MAX Qualitative Data Analysis 18.1.0 for analysis. Results: As a result of the content analysis, three main themes emerged: Psychological impact, defensive practice, and expectations from the hospital. It was revealed that, after the traumatic birth, midwives experienced highly emotional exhaustion in the form of sadness, flashbacks, guilt, fear, and empathy, and that they performed an increasingly defensive practice. Besides, midwives explicitly stated that they were not prepared enough for traumatic events and that most traumatic births were simply ignored in their workplace. Eventually, it was determined that midwives received support mostly from their colleagues in case of a traumatic birth. Conclusion(s): Midwives need to feel valued and be supported by their institutions in coping with emotional stress. Therefore, performing clinical inspections by experienced or specialist midwives may serve as a supporting framework for reducing defensive interventions.
\end{abstract}

\section{Hosted file}

Manuscript.doc available at https://authorea.com/users/325322/articles/453287-midwivesexperiences-of-witnessing-traumatic-hospital-birth-events-a-qualitative-study 


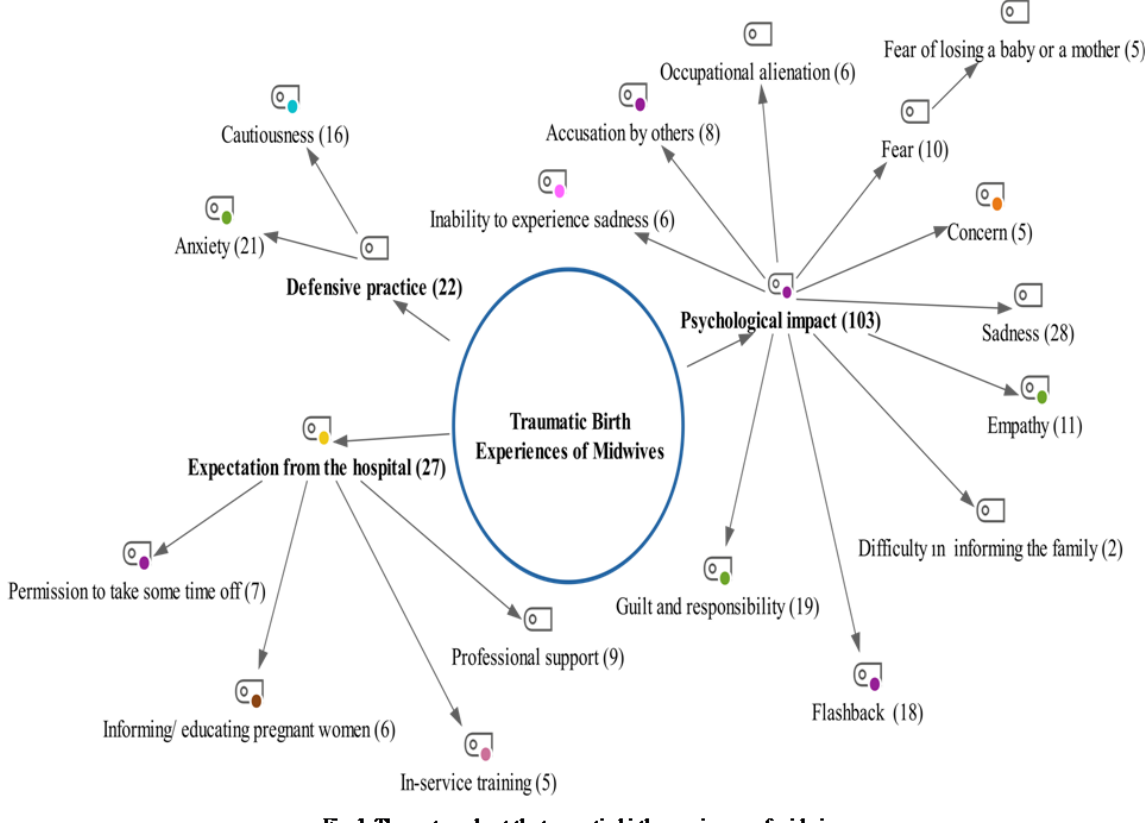

Fig 1. Theme tree about the traumatic birth experiences of midwives

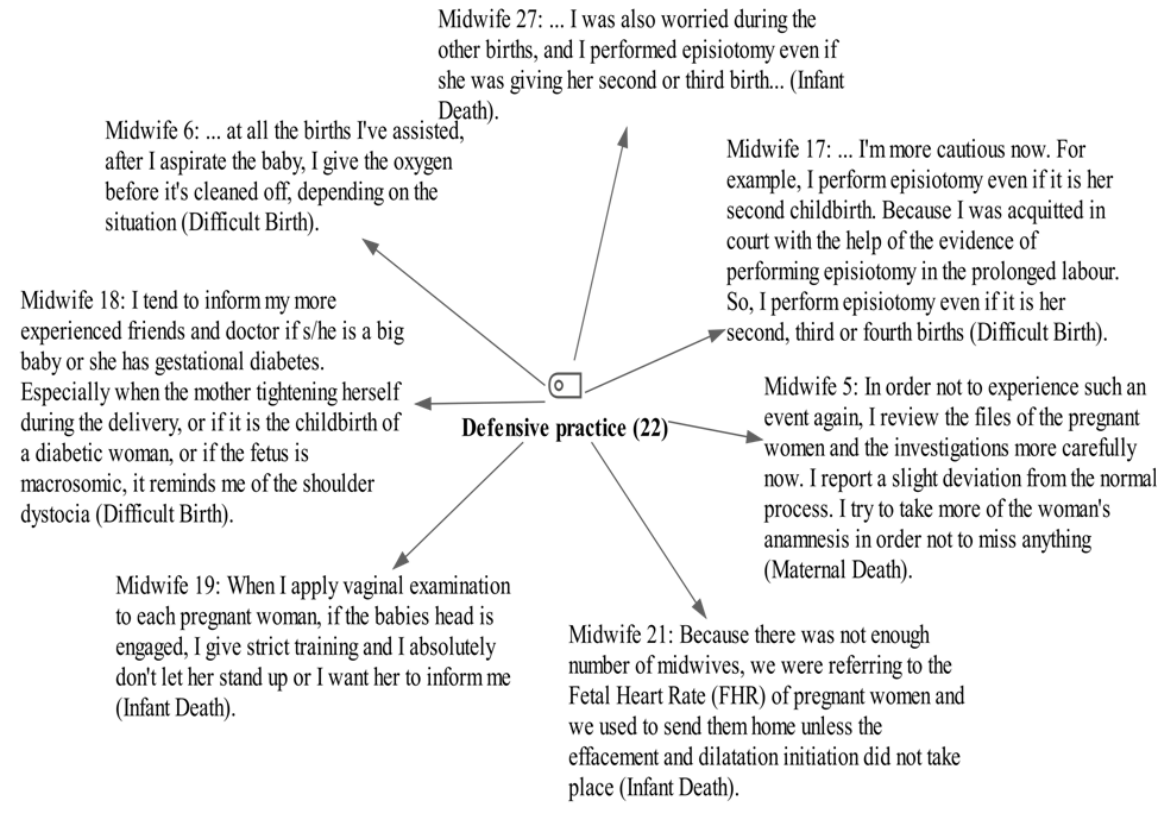

Fig 2 The views on the main theme of defensive practice 


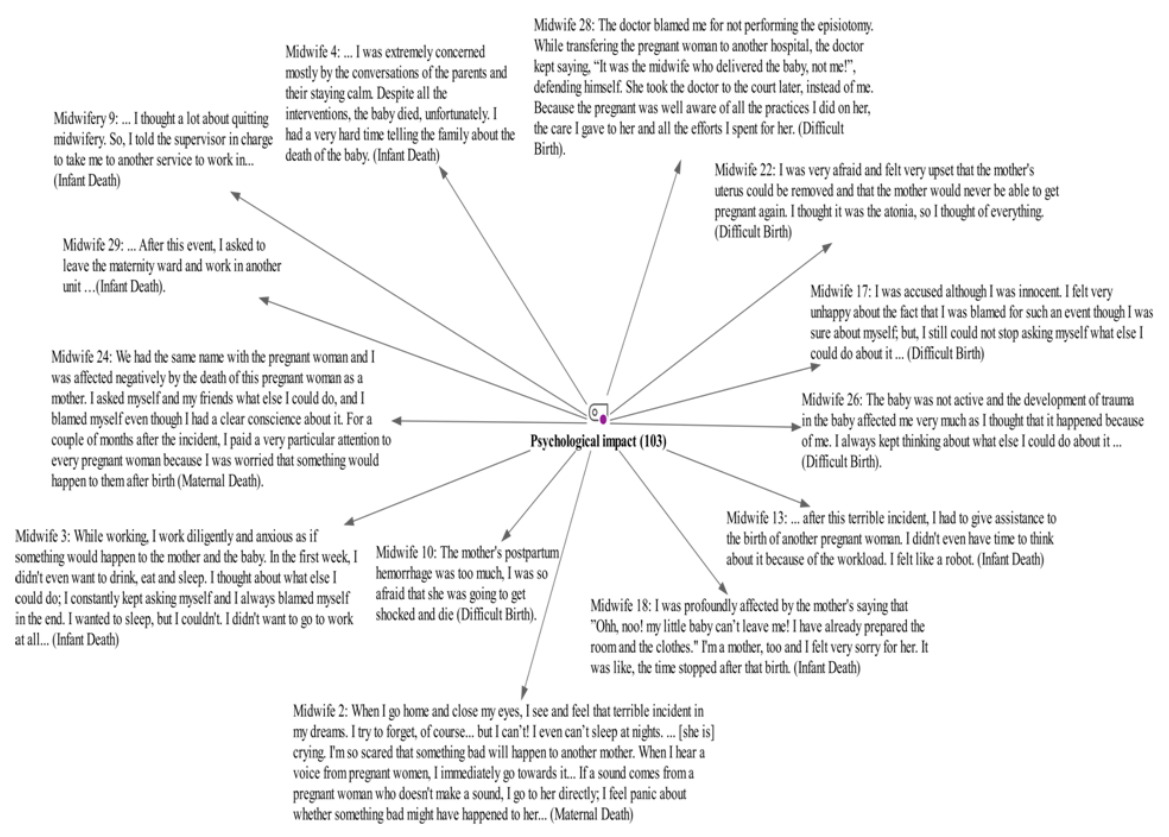

Fig 3. The views on the main theme of psychological impact

Midwife 17: ... there's a lawyer at the hospital, he could have helped me, but I was left helpless and I got my lawyer myself. (Difficult Birth)

Midwife 3: I normally welcome malpractice cases. However, in any investigation or case, if the midwife is acquitted by the experts that there is no negligence, I want and expect the hospital, where the midwife works, defend her... (Infant Death)

Midwife 2: I can't cope with these feelings right now and want to work somewhere outside the maternity ward. We experienced this horrible incident in the middle of the night $(3: 30)$, but my friend and I had to continue our shift until the morning. The supervisor could have supported us, but she didn't even ask about it at all. She should have ended our shift, and kept us away from the maternity ward immediately. I can't think of such a shocking event as hard as a mother's loss. After this incident, I had to assist another birth, but I don't even remember how I was able to assist. It was like a dream, somewhat in the middle of sleeping and staying awake. I really don't remember much about the $\nabla$ following birth. (Maternal Death)

\section{Expectation from the hospital (27)} Birth)

Midwife 20: ... We have to work days and nights nonstop; as we don't have enough personnel, we're always working. The number of personnel needs to be increased ... (Difficult

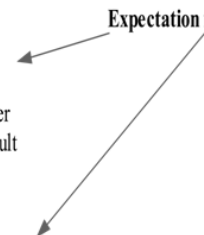

Midwife $24:$... [I was] psychologically affected. The hospital should have allowed me to take some time off, but it didn't. I was able to isolate myself from the delivery room, requesting a week off. But I myself asked for it! Even without asking, I had to be allowed in the clinic, taking my psychological situation into account. Because, after the incident, I had the feeling that every pregnant woman I was

Midwife 18: I would like to take part in training on shoulder dystocia and to be well informed about the specific manoeuvres; because when we feel panic during the delivery, we may forget all about the correct procedure. I think we have to take practical training for emergency and risky pregnants. (Infant Death)

assisting for the delivery would die (Maternal Death)

Fig. 4. The views on the main theme of expectations from the hospital 